\title{
Pelatihan Percakapan Bahasa Inggris dengan Metode Dubbing bagi Siswa Darussalam Pondok Petir-Depok
}

\author{
Yani Octafia ${ }^{1}$, Kamil Falahi ${ }^{2}$, Afrianti Wulandari ${ }^{3}$, Shandi Noris ${ }^{4}$ \\ Universitas Pamulang ${ }^{1234}$ \\ Korespondensi: dosen01153@unpam.ac.id ${ }^{1}$,dosen00482@unpam.ac.id ${ }^{2}$, \\ dosen01166@unpam.ac.id ${ }^{3}$,dosen0354@unpam.ac.id ${ }^{4}$
}

\begin{abstract}
The learning method applied in this Community Service applies the dubbing learning method. The target of the Community Service program to be targeted is the seventh grade junior high school students at the Darussalam Pondok Petir Foundation, Depok. This activity was held on 17-19 December 2020. This activity is useful for providing knowledge about the media and methods of learning English conversation in the hope that it can improve the students' ability to communicate in English. We as lecturers and students of the Faculty of Letters, majoring in English Literature, Pamulang University contributed to this activity through film media with the dubbing method to develop students' English speaking skills at the Darussalam Pondok Petir-Depok Foundation. The result of this activity is in the form of making English conversation training videos. The solution to the problems proposed by us for students at the Darussalam Pondok Petir Foundation, Depok, are students can improve their speaking skills and increase vocabulary so that they can increase the enthusiasm of students in English lessons at school and in everyday life.
\end{abstract}

Keywords: film, dubbing method, conversation, English

\begin{abstract}
Abstrak
Metode pembelajaran yang diterapkan dalam Pengabdian Kepada Masyarakat ini menerapkan metode pembelajaran dubbing. Sasaran program Pengabdian Kepada Masyarakat yang akan dituju adalah para siswa kelas VII SMP di Yayasan Darussalam Pondok Petir-Depok. Kegiatan ini dilaksanakan pada tanggal 17-19 Desember 2020. Kegiatan ini bermanfaat untuk memberikan pengetahuan mengenai media dan metode pembelajaran percakapan bahasa Inggris dengan harapan dapat meningkatkan kemampuan para siswa dalam berkomunikasi dengan bahasa Inggris. Kami sebagai dosen dan mahasiswa Fakultas Sastra, jurusan Sastra Inggris, Universitas Pamulang berkontribusi dalam kegiatan ini melalui media film dengan metode dubbing untuk mengembangkan kemampuan berbicara bahasa Inggris para siswa di Yayasan Darussalam Pondok PetirDepok. Hasil dari kegiatan ini adalah berupa membuat video pelatihan percakapan bahasa Inggris. solusi permasalahan yang diusulkan oleh kami untuk para siswa di Yayasan Darussalam Pondok Petir-Depok, yaitu para siswa dapat meningkatkan kemampuan berbicara dan menambah pembendaaraan kata sehingga dapat meningkatkan semangat para siswa dalam pelajaran bahasa Inggris di sekolah dan kehidupan sehari-hari.
\end{abstract}

Kata kunci: film, metode dubbing, percakapan, bahasa Inggris 


\section{A. Pendahuluan}

Bahasa Inggris adalah salah satu bahasa yang digunakan oleh seluruh negara dalam berkomunikasi terutama dalam bidang pekerjaan, bisnis, pendidikan, kerjasama hubungan dalam dan luar negeri dan sebagainya. Seseorang yang ingin menguasai bahasa Inggris tentunya ia harus memiliki keterampilan berbahasa. Menurut Scrinever (2005) yang harus diperhatikan dalam meningkatkan kemampuan berbahasa berkaitan dengan pengajaran bahasa adalah what we do with the language adalah apa yang kita lakukan dengan bahasa tersebut. Maka dalam kegiatan belajar mengajar diperlukan pemahaman terkait kemampuan berbahasa. Berbeda pandangan menurut Djiwandono (2011) mengenai Kemampuan berbahasa, dimana kemampuan bahasa yang baik dibagi menjadi empat jenis kemampuan bahasa, yaitu kemampuan dalam menyimak, kemampuan dalam membaca, kemampuan dalam berbicara, dan kemampuan dalam menulis. Dari paparan dua pendapat tersebut yaitu Scrinever dan Djiwandono maka dapat ditarik kesimpulan bahwa untuk mengetahui kemampuan Berbahasa seseorang maka perlu memperhatikan kemampuan dalam menyimak, kemampuan dalam membaca, kemampuan dalam berbicara dan kemampuan dalam menulis.

Semua keterampilan sangatlah penting, namun ada salah satu keterampilan yang merupakan suatu praktek yang cukup sulit bagi siswa yaitu berbicara atau speaking skill, kegiatan berbicara terdiri dari: berkata, bercerita, dan percakapan. Berdasarkan hasil survei yang dilakukan oleh tim Pengabdian Kepada Masyarakat (PKM) Universitas Pamulang, kami menemukan bahwa para siswa SMP Yayasan Darussalam khususnya kelas VII mendapatkan masalah di dalam kemampuan percakapan bahasa Inggris. Hal yang biasanya terjadi yaitu timbul kecenderungan bagi siswa tidak menyukai pelajaran bahasa Inggris karena mereka merasa kurang percaya diri dan pelajaran bahasa Inggris merupakan mata pelajaran yang menakutkan. Pada umumnya, banyak siswa yang tidak mampu atau tidak memiliki keterampilan dalam melakukan percakapan bahasa Inggris disebabkan beberapa faktor, faktor-faktor tersebut adalah faktor internal dan faktor eksternal. Menurut Soekamto (1992) pengertian dari Faktor internal merupakan segala sesuatu potensi dalam diri orang tersebut seperti temperamen, karakter, cara berfikir, persepsi, bakat/talenta, percaya diri, perhatian, kepribadian siswa, motivasi, dan tingkat inteligensia. Sedangkan faktor eksternal merupakan segala sesuatu di luar diri seseorang seperti tingkat pendidikan, pengajar, minat, bakat, kebiasaan, dan lingkungan. Berbeda menurut Arifuddin, (2010) mengenai faktor-faktor yang mempengaruhi kemampuan berbahasa Inggris yaitu faktor internal seperti bakat, usia, anggapan, aspek kognisi, motivasi, percaya diri, dan kepribadian sedangkan dan faktor eksternal seperti strategi belajar, situasi bahasa, pengajar, dan lingkungan.

Oleh karena itu kami berpendapat bahwa salah satu hal untuk meningkatkan keterampilan berbicara adalah dengan memberikan pelatihan berupa metode pembelajaran yang efektif dan efisien bagi siswa. metode dubbing melalui media film merupakan metode pembelajaran yang dapat diterapkan untuk melatih siswa berkomunikasi dengan bahasa Inggris. Menurut Susanto (1982) pengertian Film adalah suatu kombinasi antar usaha penyampaian pesan melalui gambar yang bergerak, pemanfaatan teknologi kamera, suara dan warna. Unsur-unsur tersebut di 
latar belakangi oleh suatu cerita yang mengandung pesan dan ingin disampaikan oleh sutradara kepada khalayak film. Sebuah film juga membawa pesan-pesan komunikasi untuk diperlihatkan pada penonton, sesuai yang ingin diberikan oleh sutradara seperti dalam drama, komedi, horor, dan action. Selain itu, beberapa tokoh selain Susanto dapat mendefinisikan film dengan berbagai macam pemikirannya, seperti pendapat Arsyad (2003) mendefinisikan film seperti kumpulan dari beberapa gambar yang berada di dalam frame, dimana frame demi frame diproyeksikan melalui lensa proyektor secara mekanis sehingga pada layar terlihat gambar itu menjadi hidup. Film bergerak dengan cepat dan bergantian sehingga memberikan daya tarik tersendiri. Berbeda pendapat Baskin (2003) dalam mendefinisikan film seperti salah satu bentuk media komunikasi massa dari berbagai unsur-unsur kesenian dan berbagai macam teknologi.

Dalam kegiatan ini adalah metode yang dipakai adalah teknik dubbing yang merupakan metode sulih suara cuplikan film yang melibatkan peran aktif para siswa dalam menentukan sendiri arah percakapan tokoh dalam cuplikan tersebut. Metode ini mempersilahkan siswa untuk mengganti suara pemeran film dalam video dengan suara mereka sendiri yang naskahnya mereka buat sendiri. Metode dubbing juga dapat menerjemahan, khususnya percakapan bahasa Inggris dalam sebuah film sehingga ada proses pembelajaran bahasa Inggris. Sesuai dengan pendapat Baker (2001) bahwa "since 1929, when the first sound films reached an international audience, two methods have been dominant: subtitling and dubbing", menurut Baker bahwa untuk menarik perhatian penonton dan memperoleh pemahaman penonton terhadap film asing dapat digunakan metode dubbing. Metode dubbing adalah menirukan suara aktor yang berperan dalam sebuah film.

Kami sebagai pelaksana kegiatan ini menentukan pemilihan judul film yang sesuai untuk para siswa tingkat kelas VII SMP. Film yang dipilih tentunya adalah film Indonesia. Dosen membimbing mahasiswa untuk menentukan judul film yang akan dipilih. Berhubung Kegiatan ini di tujukan untuk kelancaran bahasa Inggris siswa Indonesia, maka kami memilih serial film anak-anak Indonesia; film berasal dari negara indonesia sendiri yaitu serial anak, Adit Sopo Jarwo. Seperti kita ketahui, banyak siswa yang tidak mampu atau tidak memiliki keterampilan dalam melakukan percakapan bahasa Inggris disebabkan beberapa faktor yaitu minimnya kosakata, kurang faham bagaimana pronunciationnya, factor kurang terbiasa dan kurang percaya diri atau mungkin juga guru kurang membimbing dan memotivasi siswa dalam berlatih. Maka dari itu perlu sering dilakukan pelatihan-pelatihan yang bertujuan untuk mengasah keterampilan berbicara mereka sehingga meningkatkan motivasi siswa terhadap keterampilan berbicara bahasa Inggris.

\section{B. Pelaksanaan dan Metode}

Sasaran program pengabdian kepada masyarakat yang akan dituju adalah para siswa kelas VII SMP di Yayasan Darussalam Pondok Petir-Depok. Pelaksanaan kegiatan pengabdian berlangsung pada hari Kamis- Sabtu, 17-19 Desember 2020. Mengingat saat ini dalam keadaan pandemi Covid-19, maka kegiatan ini berlangsung diruang kelas Prodi Sastra Inggris kampus Viktor, Jalan 
Raya Puspitek, Tangerang Selatan. Kegiatan ini dimulai dengan penyampaian materi-materi pokok, tahapan-tahapan kegiatan yang berhubungan dengan media pengajaran, dan metode pembelajaran percakapan bahasa Inggris. Adapun metode kegiatan ini adalah sebagai berikut:

1. Menentukan pemilihan judul film yang sesuai untuk para siswa tingkat kelas VII SMP.

2. Menentukan pembagian peran untuk pengisi suara (dubber).

3. Melakukan persiapan bahan dan alat pendukung

4. Melakukan penulisan script

5. Melakukan proses translate dari bahasa Indonesia ke bahasa Inggris

6. Melakukan proses dubbing

7. Melakukan proses editing/ penyuntingan dubbing.

8. Persiapan materi

9. Pembuatan slide untuk video

10. Penyuntingan video

11. Finalisasi video pembelajaran

\section{Hasil dan Pembahasan}

Kami sebagai dosen dan mahasiswa Fakultas Sastra, jurusan Sastra Inggris, Universitas Pamulang mengadakan kegiatan pengabdian kepada masyarakat berupa kegiatan dengan judul Pelatihan Percakapan Bahasa Inggris Melalui Media Film Dengan Metode Dubbing Pada Siswa Yayasan Darussalam Pondok Petir- Depok. Dalam pelaksanaannya pada kegiatan ini ada beberapa tahapan metode pelaksanaan. Pada setiap tahap dapat dilihat dan dihasilkan luaran yang diharapkan seperti:

1. Menentukan pemilihan judul film

Menentukan pemilihan judul film yang sesuai untuk para siswa tingkat kelas VII SMP. Film yang dipilih tentunya adalah film Indonesia. Dosen membimbing mahasiswa untuk menentukan judul film yang akan dipilih. Berhubung kegiatan ini di tujukan untuk kelancaran bahasa Inggris siswa Indonesia, maka kami memilih serial film anak-anak Indonesia; film berasal dari negara indonesia sendiri yaitu serial animasi anak, Adit Sopo Jarwo yang diproduksi oleh MD Animation. Pada tanggal 27 Januari 2014 serial animasi anak yang berjudul Adit Sopo Jarwo dirilis di Indonesia dan film ini pertama kali disiarkan di MNCTV. Adapun alasan kami memilih serial ini karena ceritanya cukup bagus dan memberikan banyak pelajaran untuk anak-anak.

Film ini menceritakan kisah persahabatan antara Adit, Mitha, Dennis, dan Devi serta simungil Adelya yang kehidupannya diwarnai petualangan-petualangan tak terduga. Film ini di produseri oleh Dana Riza, Manoj Punjabi, Dhamoo Punjabi, dan Shania Punjabi. Karya ditulis oleh Yulie Odang. Film inipun pernah mendapatkan penghargaan Panasonic Gobel Award untuk program anak terfavorit.

2. Menentukan pembagian peran untuk pengisi suara (dubber).

Tim dosen membimbing tim mahasiswa dalam pembagian peran dan pengisian suara (dubbing). Dubber terdiri dari 3 mahasiswa dan 3 mahasiswa yang sedang 
menempuh semester 6-7 jurusan sastra Inggris dan mereka mengisi suara untuk 11 peran/pemain di serial Adit Sopo Jarwo tersebut. Adapun peran-peran nya adalah sebagai berikut:

- $\quad$ Samuel mengisi suara untuk peran Adit

- Chairunnisa mengisi suara untuk peran Sopo dan Ucup

- $\quad$ Denal mengisi suara untuk peran Jarwo, Kipli dan Bang Ujang

- $\quad$ Ita mengisi suara untuk peran Denis

- Nabila mengisi suara untuk peran Devi, Nia dan Nita

- $\quad$ Panji mengisi suara untuk peran Bpk. BJ Habibie

3. Melakukan persiapan

Persiapan kegiatan ini berupa bahan-bahan dan alat pendukung yaitu berupa film sebagai media pengajaran percakapan bahasa Inggris dan memberi arahan metode dubbing untuk pembelajaran percakapan bahasa Inggris. Tim Dosen membimbing Tim mahasiswa untuk menyiapkan bahan-bahan dan alat pendukung tersebut.

4. Penulisan script

Tahapan berikutnya adalah dosen membimbing mahasiswa dalam melakukan penulisan script atau dialog percakapan yang ada pada scene film yang dipilih, adapun episode yang tim pilih berjudul "Adit Sopo Jarwo dan Eyang B.J Habibie".

Kisah pertemuan Pak Habibie dengan Adit dan teman-temannya di Kampung Karet Berkah tersebut disiarkan dalam serial Adit \& Sopo Jarwo di episode 7677. Setiap Episode memiliki tema berbeda, namun dalam kesatuan cerita sejak kedatangan Pak Habibie membuat keterpesonaan mereka semua selepas mendengarkan motivasi dari Pak Habibie. Episode ini tayang pada 28 Agustus 2019 dan ditayangkan ulang pada 13 September 2019, dua hari setelah Pak Habibie meninggal dunia. Dari episode ini, Tim hanya mengambil 2 scene.

5. Translating

Setelah penulisan script pada metode ke-4, tahapan berikutnya adalah proses translating yaitu menerjemahkan bahasa dari script bahasa Indonesia ke script bahasa Inggris. Dialog-dialog yang ada pada episode "Adit Sopo Jarwo dan Eyang B.J Habibie" tersebut ditranslate atau diterjemahkan kedalam bahasa Inggris. Penulisan/ translating dialog atau percakapan tersebut di di review dan revisi oleh dosen, baik secara grammar, vocabulary maupun spelling. Berikut script yang sudah di diterjemahkan ke dalam bahasa Inggris oleh tim mahasiswa.

\section{Scene I}

Habibie : Assalamualaikum Denis.

Denis : Waalaikum salam eyang. Really missing you Eyang.

Habibie : You've grown up so fast, my grandson, thanks God.

Adit : Welcome to Karet Berkah Village eyang. I'm Adit eyang.

Kipli : Hi eyang I'm Kipli.

Nia : Hello eyang I'm Nia.

Devi : I'm Devi eyang. 
Nita : Nice to see eyang, I am Nita.

Bang Ujang : And I'm Ujang.

Ucup : Hi Eyang, I'm Ucup. Oooh eyang have made the plane, right?

The one who studied to german, right? The third President? I'm very fond of you.

Bang Ujang : Excuse me eyang, there's a warm bowl of balls for us aircraft maker.

Habibie: Thank you so much Ujang.

Ucup : You're welcome eyang

I feel like a great person like you might love my dream of a meatball

Habibie: This meatball is really tasty.

Bang Ujang : Are you serious? So glad to hear that!

Habibie : This meatball is so yummy, it tastes good. Remembering of my favorite meatball when I was young.

Adit : Where did you live eyang?

Habibie: At the time, I went to germany and stayed in a cheap suburb apartment without a toilet and I was going to school on foot. My target was only one, made planes for the Indonesian my beloved country. When I was 18 years old, I made an aircraft model, and I had already determine how to fly it. I manipulated the heat energy of the movement sound such that the pressure decreases.

Adit: Woow, that's cool! Eyang.

Habibie: As a result, the wing is under pressure from the bottom up, so it must be calculated if the plane crashes.

Bang Ujang : Woow, its really great!

\section{Scene2 (In the field)}

Habibie: So that this aircraft can contact every island on the Indonesian continent".

Therefore, on August 10, is remembered by the whole Indonesian nation as the revival of national technology.

Ucup : Yeay, Eyang Habibie is really great!

Habibie : The N-250 Gatot Kaca was the most advanced class the world knew at that time.

Ucup : That really great Eyang!! I'm proud of you Eyang!!

Jarwo: Wow, there is a Habibie Eyang, always healthy, okay? Wow, this is really great, has provided inspiration.

Habibie : Denis..

Denis : I am, Eyang?

Habibie: You are an Indonesian son who can prove, you can engineer anything the most sophisticated as a Gatot Kaca. You have to be confident, don't be ashamed, don't be afraid, remember the message! Okay?

Denis : Okay Eyang.

Habibie : In the future, what do you want to be Denis? 
Yani Octafia, Kamil Falahi, Afrianti Wulandari \& Shandi Noris

Denis : I want to be the Pilot eyang..

Habibie : Pilot? Very nice. How about Ucup?

Ucup : I really want to be an Ustadz eyang

Habibie: That's good, so that Indonesian people will have good morals

by learning their respective religions with you. Devi, your turn?

Devi : I Want to be a designer, eyang.

Habibie: What kind of the designer, Devi?

Devi : The Designer of Clothes Eyang.

Habibie: Oh that's great. Wishing your dream come true. How about you Kipli?

Kipli : Then I dream of to be a Soldier, like a gentle man Eyang.

Habibie: Oh, want to be a brave soldier right? Really good. Well Nia?

Nia : I want to be Kindergarten teacher.

Habibie : Kindergarten teacher? It's so nice. Preparing as early as possible. Then, Adit?

Adit : Adit always want to be the President, just like you.

Habibie : Waah the President? It's a great dream, why not?

Jarwo; Eyang, I wish to be an Indonesian person who is useful for the nation, state and religion. Sopo, what do you want to be?

Sopo : I will do the Hajj trip with my mother.

Habibie: I definitely sure that all of you can achieve your goals and your dreams, because you dreams are real. You are free humans who have the same right as other nations.Dare to make your dreams come true. Start where you are. Use what you have. Do what you can. "The future belongs to those who believe of their dreams for their beloved country.

Then you can be the pride of the Indonesian people"

6. Proses dubbing

Setelah pembagian peran pada metode tahapan kedua, tahapan berikutnya adalah proses dubbing yaitu mengisi suara, yang mana mahasiswa mengganti suara asli padaa animasi tersebut dengan suara mereka sendiri. Sebelum mahasiswa melakukan dubbing, mereka sudah latihan berkali-kali agar tidak terdapat kesalahan baik secara spelling, pronounciation maupun intonasi.

7. Editing

Setelah semua mahasiswa melakukan teknik dubbing maka tahap berikutnya adalah melakukan proses editing/penyuntingan yaitu memasukan suara dubber yang sudah lengkap satu episode kedalam film tersebut.

8. Persiapan materi

Setelah proses editing selesai, dosen mempersiapkan materi tentang percakapan bahasa Inggris (speaking skill), materi tentang media film dan materi tentang metode dubbing, yang mana materi itu akan disisipkan di slide video yang akan diberikan kepada mitra untuk para siswa Yayasan Darussalam Pondok Petir, Depok.

9. Pembuatan slide untuk video

Dosen membuat slide untuk kegiatan ini yang berisi tentang: 
- Pengenalan tim dosen Sastra Inggis, Universitas Pamulang

- Pengenalan mahasiswa sebagai pemeran dis serial Adit Sopo Jarwo dan Eyang B.J Habibie

- Video Adit Sopo Jarwo dan Eyang B.J Habibie yang sudah berisi suara mahasiswa sebagai pelaku dialognya dalam bahasa Inggris

- Ucapan terimakasih

10. Penyuntingan video

Mahasiswa menyunting slide video yang telah dibuat dosen, slide video tersebut dibuat semenarik mungkin agar para siswa Yayasan darussalam, semakin semangat dalam menyimaknya

11. Finalisasi video pembelajaran

Tahap berikutnya adalah finalisasi video pembelajaran, slide video ini diberikan kepada mitra yaitu Yayasan Darussalam Pondok-Petir, Depok.

\section{Penutup}

\section{Simpulan}

Berdasarkan hasil kegiatan yang telah kami lakukan di Pengabdian Kepada Masyarakat ini, dapat kami simpulkan bahwa:

1. Hasil yang dicapai bertambahnya keterampilan dan kemampuan speaking skill anak-anak binaan dan pengurus Yayasan Darussalam Pondok Petir, Depok.

2. Pemanfaatkan media film dan metode dubbing dapat digunakan dengan baik.

\section{Saran}

Berdasarkan hasil kegiatan yang telah kami lakukan di Pengabdian Kepada Masyarakat ini, dapat kami berikan saran untuk kegiatan dimasa yang akan datang sebagai berikut:

1. Pelatihan sejenis ini dapat dilakukan persemester.

2. Perlu dibuatnya secara pelatihan-pelatihan dibidang bahasa Inggris lainnya agar dapat bertambah pengetahuan.

\section{DAFTAR PUSTAKA}

Arifuddin. (2010). Neuro psikolinguistik. PT Rajagrafindo Persada.

Arsyad, A. (2003). Media pembelajaran. PT Raja Grafindo Persada.

Baker, M. (2001). Routledge encyclopedia of translation studies. Routledge.

Baskin, A. (2003). Membuat film indie itu gampang. Kanisius.

Djiwandono, M. S. (2011). Tes bahasa pegangan bagi pengajar bahasa. Indeks.

Pradana, S. A. (2016). The use of videocast in improving the speaking ability integrated in a drama class. English Education: Jurnal Tadris Bahasa Inggris, 409-428.

Sanjaya, W. (2010). Strategi pembelajaran berorientasi standar proses pendidikan. Kencana.

Scrivener, J. (2005). Learning teaching: a guide book for English language teachers. Macmillan Education. 
Yani Octafia, Kamil Falahi, Afrianti Wulandari \& Shandi Noris

Soekamto, T. (1992). Strategi belajar mengajar. BP-FKIP UMS.

Susanto, A. S. (1982). Komunikasi massa. Bina Cipta. 